\title{
FORMA-R: DE-FORMA-R: TRANS-FORMA-R:
}

\section{TO FORM: TO DIS-FORM: TO TRANS- FORM:}

\section{Alda Regina Tognini Romaguera}

\section{$\underline{\text { Assista ao vídeo Pulsar }}{ }^{1}$}

Escrita-mapa-convite, passaporte para nos admitir em outro território: o da dúvida; uma provocação que se inicia com a projeção de imagens, concebidas para pensar pelo avesso, ao contrário, as questões educacionais na contemporaneidade. O convite ao embarque que aqui se apresenta pretende traçar outras rotas, menos previsíveis, que levem a abdicar do conforto, da segura âncora histórica oferecida por pedagógicos textos, para transitar pelos incertos caminhos do agora.

Estas imagens foram geradas a partir de fragmentos de escrita, que compus de repente, que me tomaram o pensamento e se fizeram textos. Já que se manifestaram assim, como um nascimento sem gestação, imaginei outros jeitos para apresentá-los, que não apenas pela palavra escrita: com imagens, posto que os queria em movimento. Mais que isto, queria que pulsassem e que provocassem sensações em quem os assistisse, que deslocassem o olhar habituado para incomodar, produzir efeitos.

Texto que traduz minha vontade de pensar educação e arte, cuja proposta é a de explorar uma educação dos sentidos:

\section{FORMA-R: DE-FORMA-R: TRANS-FORMA-R:}

\section{Palavras pulsantes}

Ao chacoalhar os vocábulos que nomeiam este texto, pulsaram e escapuliram letras que se desalinharam e me provocaram a pensar alguns dos aspectos da educação que vibram nestas palavras. Da palavra-valise forma derivam movimentos, ondulações semânticas

\footnotetext{
${ }^{1}$ http://www.vimeo.com/1609590
} 
prefixais que a negam ou a atravessam, sem no entanto ultrapassá-la, perfurá-la, roubando-lhe o sentido. Aproximando este substantivo feminino - forma - do outro - educação -, foi possível ensaiar passos para uma dança vocabular. Inicialmente busquei em Houaiss a etimologia da palavra educação, que deriva do latim educatìo e comporta a 'ação de criar, de nutrir; amamentar, cuidar, educar, instruir, ensinar'; cultura, cultivo'. Repetindo o procedimento para o vocábulo forma, resultam múltiplos sinônimos, dentre os quais: formato, feitio, figura; estado físico sob o qual se apresenta um corpo, uma substância etc.; aparência física de um ser ou de uma coisa; um ser ou objeto indistinto, percebido imprecisamente; modo, jeito, maneira, método.

Dá vontade de virar do avesso esses exercícios de recognição. Amorfar a forma, morfa. Agramaticar a educação.

Se palavras nomeiam coisas e procedimentos, com Deleuze e sua proposta do pensamento por experimentação é possível pensar outras abordagens para as palavras, fora do campo da representação, tornando-as múltiplas. Operar na vivência, na duração intensa e intensiva de um tempo aiônico, do infinitivo do verbo. Com este procedimento, transformálas em palavras pulsantes. Em seus pulsares, perceber matizes e nuances de cores, sons, formas, que abrem possibilidades para propor movimentos, danças vocabulares.

Gestos que abrem espaços vazios para outras composições, possibilidades de entrar pelo entre-aberto em palavras. A expressão deve despedaçar as formas, marcar as rupturas $e$ as ramificações novas. Estando despedaçada uma forma, reconstruir o conteúdo que estará necessariamente em ruptura com a ordem das coisas. Antecipar, adiantar a matéria. (DELEUZE; GUATTARI, 1997, p. 43-44).

Segmentar sem silabar, apenas des-construir, desconectar o nome da coisa. Considerar a coisa em si para pensar em espaços, hiatos, dobras naquilo que nomeamos Educação. Abrir fendas por entre as letras e dar-lhes uma chance de pulsar, mexendo-se. Provocar o soluço da língua, exercício de gagueira na palavra Educação, abrindo brechas ao pronunciar educa-duca-ção; caduca-ção...

Com Deleuze, des-territorializar procedimentos, experimentar sensações invertendo os sentidos do nomeado, abrindo os poros para percepções mais integrais, de corpo inteiro. Julia Almeida aproxima Filosofia da diferença de Literatura e dobra/des-dobra a teorização 
lingüística fundada em uma matriz bidimensional, representada pelo par palavra-coisa, na proposta de:

\begin{abstract}
“abrir as palavras”, para: “... extrair das palavras e da língua os enunciados que integram estratos e seus limiares” e "abrir as coisas”, de forma a: “... extrair das coisas visibilidades como construtos próprios de um estrato, provocando a aparição do enunciado de delinqüência” (ALMEIDA, p. 63).
\end{abstract}

Enunciado de delinqüência que vibra nos escritos poéticos de Manoel de Barros, assim: Sei que fazer o inconexo aclara as loucuras. Sou formado em desencontros. A sensatez me absurda. Os delírios verbais me terapeutam. (2006, p.49).

\title{
Varal de palavras
}

Pensar nomes em conexão com gestos. E desta aproximação, recolher a pulsão da palavra-valise Educação. Desmontá-la inicialmente em dois fragmentos, intensificando o que tensiona em Educa: enforma, formata. Considerar o vocábulo Fôrma na sua modalidade molde, modelo, encaixe, desenho, formato da coisa. Esticar o fragmento Ação, movimentando sua forma - fazer, procedimento, deixando que pulse na palavra Forma o modo de fazer, jeito de proceder, a maneira. Deste estiramento vocabular, abrir o leque da idéia de Educação para problematizá-la: Fôrma que se forma? Forma de enformar? En-formação... Des-enformar a escrita - do lugar/prisão/território: escola - para despi-la de sua forma-fôrma aprisionada na linguagem educacional, num delírio verbal, que se deixa:

\section{Escrever menormente:}

No menos, somente.

Em perigo, totalmente.

Redemoinhando e dançando no meio da rua:

Gente,

Gente,

Gente.

Palavras tecidas

rasgadas em tiras,

farrapos. 


\section{Forma-r - de-forma-r - trans-forma-r}

Palavras-resto esfarrapadas,

farfalhando por

superfícies manchadas,

territórios molhados,

espaços tingidos:

\section{Forma-r - de-forma-r - trans-forma-r}

Varal de palavras borradas por jorros de tinta

Farrapos piscantes,

Restos inconstantes,

Metamorfoseados:

Papa do de-trans-forma-r

\section{Pulsar}

Criaturas

\section{Caricatas}

Caricaturas

Criaturidade

\section{Pulsar}

Caetano Veloso/Augusto de Campos

Onde quer que você esteja Em Marte ou Eldorado Abra a janela e veja O pulsar quase mudo Abraço de anos-luz Que nenhum sol aquece E o oco escuro esquece

C Editora Gapa

$$
\begin{gathered}
\text { prismas em Pink Floyd: } \\
\text { particulas? } \\
\text { ondas? } \\
\text { Fluxos caleidoscópicos }
\end{gathered}
$$


Gestos de chacoalhar em que se pretendem caleidoscópicos fluxos no movimento de esparramar letras, despregando-as dos objetos, nomes e procedimentos que antes nomeavam. E no remelexo, inventar outros jogos, propor formatos outros para o procedimento de educar. Sugar do poeta a vibração artística, já que:

Arte não tem pensa:

O olho vê, a lembrança revê, e a imaginação transvê.

É preciso transver o mundo.

Isto seja:

Deus deu a forma. Os artistas desformam.

É preciso desformar o mundo:

Tirar da natureza as naturalidades.

Fazer cavalo verde, por exemplo.

Fazer noiva camponesa voar - como em Chagall. (BARROS, 2006, p.75).

Abrir-se a novas arquiteturas do educar, sem pressupor o gesto, apenas exercitando esboços, rascunhos, ensaios. Possibilidades de pensar a aproximação da arte em sua pulsão estética com maneiras de desformar a educação. Tirar da educação suas naturalidades, fixadas em currículos e metodologias que não nos deixam transver o mundo. Esvaziar toda a substância educacional que pesa, que não se deixa digerir, que não nos deixa dançar - no dizer de Nietzsche - nem fazer a educação voar... Assim como noivas em Chagall.

Esta busca por uma educação como experimentação, pelo contato vicinal, convida a quem se dispõe enveredar por corredores e salas, permitindo-se sentir o escorrer e o pulsar do sangue nas veias, no ritmo de batidas cardíacas, no compasso da respiração, vivendo intensidades pelas entranhas viscerais e não pelo fora epidérmico.

Sentir a educação pulsar não se propõe a significar relações a partir de elementos dados, endurecidos, assim como as que aparecem no par ensino-aprendizagem. Posto que o aprendizado escorre, foge ao controle, antes quer pensar do que se compõe suas entranhas; deixar-se impregnar, empapuçar-se na substância e aceitar as vísceras no/do contato com os outros: educasensação. Quer prospectar a educação, ir atrás do que não está dado, propor uma educação ao contrário para perceber o que se pode liberar na/da educação, por suas intensidades: educacionalidade, trabalhando com a idéia de educação como potência, força 
que gera excessos, abrindo-a para os barulhos ensurdecedores, tonalidades e movimentos que se efetuam num

\section{Ritornelo Non-sensorial:}

Olhos de escutar: silêncios: rumores

Ouvidos de ver: radares: sensores

Bocas pra cheirar: ventosas: humores

Narizes de comer: paladares: vorazes

Educacionalidade, educasensação: Ensaiar os olhos até conseguir escutar silêncios. Suportar na pulsação do silêncio a sua musicalidade, seus tons de espera, de pausa. Extrair dos espaços vazios de sons a potência da escuta. Perceber rumores, murmúrios. Afinar os ouvidos até que eles enxerguem, até que se tornem radares, sensores... Enxergar, na mistura de cores, os brilhos e os pulsos luminosos do abrir e fechar dos olhos, vaga-lumeando percepções de mundo.

Abrir a boca até que ela capture cheiros, sugando humores, por mucosas metamorfoseadas: ventosas... Degustar e deglutir, comer o mundo pelos olhos, narinas e boca, e fartar-se. Aspirar, com vorazes narizes, paladares possíveis que anunciam prazeres do cheiro e do gosto. Soprar palavras que se espalham: hálito, vento-ventania, barulhando formas, amorfas, coloridas, dançantes.

\section{De-trans-forma-r}

De-trans-forma-r a educação: deixar fluir, escorrer, desabar, sem pretensão de reconstruir. Permitir-se conviver com o arruinamento, o desmoronamento. Desinventar a educação. Olhar com olhos crus, despi-los das róseas lentes da pedagogia moral e saber que o gesto de educar é pulsante, balançante e bagunçante das certezas. Assim como a poesia...

Se, para Manoel de Barros ${ }^{2}$ : Para entrar em estado de árvore é preciso partir de um torpor animal de lagarto às três horas da tarde, no mês de agosto, o processo de ser uma

\footnotetext{
2 www.eduquenet.net/images/fotmbarros.jpg, consultado em 29/06/2007.
} 
árvore só se completa quando os galhos nascem do próprio corpo, saindo da voz. Tornar-se a coisa, ser a coisa em seu estado mesmo. É o delírio da sintaxe, em que substantivos ganham qualidades inusitadas, gerando um sentido completamente novo, totalmente "desacostumado".

Ao escrever apenas o rumor das palavras, sem dar-lhes significado, o poeta as aproxima de coisas, de objetos que podem ser quase tocados, assim: Em dois anos a inércia e o mato vão crescer em nossa boca. Sofreremos alguma decomposição lírica até o mato sair na voz. (BARROS, 1993).

Ou ainda, para que se exercite a decomposição em:

Giros de pratos equilibristas na comprida mesa do circo, passos apressados, braços atarefados, pratos espatifados.

Se a educação pode ser pensada como um movimento dos campos de pensamento, é preciso desalojar-se das certezas, evitar a formulação de perguntas que pressupõem respostas. Apostar na educação como dança, como que tradução de movimentos, como que em pulsação; para que não seja nem isto nem aquilo, conectando-se pelo ou, mas que seja $e$ isto, $e$ aquilo, $e$ aquilo outro, $e$ outra vez, posto que conectada pelo $e$ : ensaios de orquestra, em arremedo felliniano.

Nesta seqüência de imagens e leituras fiz um convite para pensar o vocábulo Educação em sua potência múltipla, pluralizando-o para abarcar sentidos de: homens, mundos, sociedades, conhecimentos, aprendizagens. Com estas imagens, podemos assumir vias, veredas e trilhas, que nos arrastem para outras buscas...

Professorar na contemporaneidade pode nos convidar ao embarque em viagens para o caos. Esta nova rota se propõe a desestabilizar viajantes que antes rumavam para o futuro, convidando-os a passear, a deslocar-se por intensidades de fluxos em direção ao devir. Proposta de exercitar uma relação mais móvel, sem fixidez, mais nômade, que aconteça em espaços horizontalizados, em rede, sem fronteiras. 


\section{REFERÊNCIAS}

ALMEIDA, J. Estudos deleuzeanos da linguagem. Campinas: Editora da Unicamp, 2003.

AMORIM, A. C. R . Nos limiares de pensar o mundo como representação.Pro-Posições, Campinas: UNICAMP. v. 17, n. 1, p. 177-194, 2006.

BARROS, M. O livro das ignorãças. Rio de Janeiro, Record, 1993.

. Livro sobre nada. Rio de Janeiro, Record, 2006.

DELEUZE, G.; GUATTARI, F. Kafka, por uma literatura menor. Rio de Janeiro: Imago, 1977.

FOUCAULT, M. As palavras e as coisas. São Paulo: Martins Fontes, 2002.

GALLO, S. Deleuze \& a Educação. Belo Horizonte: Autêntica, 2005.

HOUAISS. Dicionário eletrônico. Disponível em:

<http://www.dicionariohouaiss.com.br/dicionario>. Acesso em: jul. 2007.

ALDA REGINA TOGNINI ROMAGUERA

Pedagoga; atualmente exerce as funções de coordenadora pedagógica de

Ensino Fundamental na Escola do Sítio, em Campinas; de orientadora educacional da Faculdade Municipal Prof. Franco Montoro, em Mogi-Guaçu; de professora de cursos de graduação e pós-graduação em Pedagogia e

Psicologia, ministra disciplinas nas áreas de Metodologia, Currículo e

Filosofia.

Instituição e complemento: UNICAMP - Faculdade de Educação - OLHO

E-mail: aldaromaguera@hotmail.com 